\title{
Biopharmaceutical innovation: benefits and challenges
}

\begin{abstract}
There is an urgent need for new discoveries and development in biodrugs field. Indeed, the continuous development mutations of viruses and microbes and the emergence of distinct types of diseases along with numerous patients with specific cases push the industrial and biopharmaceutical sectors to collaborate with each other to innovate and develop new biodrug to face this dilemma and serve the interest of all mankind healthcares. This would lead to an increase in the lifetime expectancy and an improvement of life quality via providing better therapies. However, the biopharmaceutical innovation faces numerous challenges and difficulties before giving birth to a new biodrug but this did not stop it from discovering and boosting the development and innovation of drugs with huge benefits and better health outcomes for the population. Such development improves the quality of life for the society and the coming generations. Within this review, we describe selected examples that illustrate the benefits of the biopharmaceutical innovation as well as the related challenges.
\end{abstract}

Keywords: biopharmaceutical innovation, Benefit, Challenge, Innovation of drugs

\author{
Volume I Issue I - 2017
}

\author{
Kadour Ghanemi,' Shuangsheng Yan² \\ 'Department of Business Management, School of International \\ Pharmaceutical Business, China Pharmaceutical University, China \\ ${ }^{2}$ Department of Social Science, School of International \\ Pharmaceutical Business, China Pharmaceutical University, China
}

\begin{abstract}
Correspondence: Shuangsheng Yan, Associate Professor, Director, the Philosophy of Teaching and Research Office, Department of Social Science, International Pharmaceutical Business School, China Pharmaceutical University, Longmian Avenue, Jiangning District, Nanjing, P.R. China, 21 I 198, China, Tel +8613305151 7 82, Email yss@cpu.edu.cn
\end{abstract}

Received: June 30, 2017 | Published: July 07, 2017

\section{Introduction}

One day we may look back at the last era and notice that there were huge development and progress in the field of biopharmaceutics. The innovation is considered as fundamental for the evolution and development of the biopharmaceutical manufacturing. ${ }^{1}$ Although the remarkable modern advances, the overall rate of divers' diseases and health problems is still rising, the biopharmaceutical and healthcare professionals are working hard and continuously to control this dilemma. ${ }^{2}$ Nowadays, changes in the biopharmaceutical fields are clearly noticeable. While novel biopharmaceutics and new drugs development tools are discovered and improved, the improvement and the development of the biotechnology is the impulse of this development. ${ }^{3}$ However, biopharmaceutical innovation is facing numerous challenges from different sides to innovate and promote the newly-developed biodrugs. However, this did not stop the biopharmaceutical companies, the researchers in the related fields and the pharmacists to continue their noble work and innovate more, because the biopharmaceutics are among the most important approaches to shape and improve the healthcare, extend healthy productive longevity and reduce the spread of severe diseases. Moreover, the biopharmaceutical innovation represents also a key for development and a successful leadership toward boosting the industrial production, such innovation represents also a factor of economic growth and it ensures its competitiveness in the global market ${ }^{4}$ at the international level.

\section{The benefits and outcomes of the biopharmaceutical innovation: selected examples}

One of the most important objectives of the biopharmaceutical innovation is to contribute in the decrease of mortality and premature death averages. Recently the Manhattan institute published a research study about the reasons why the average of lifetime expectancy and longevity varies from a country to another, the effective contribution of new biodrugs proves that the more we use new biodrugs the more we gain longevity and provide welfare to the population. ${ }^{5}$ In addition, adapting drug formulations to specific patients and cases leads to improved cures and premature mortality reduction, which is a substantial public health goal too? Since the biopharmaceutical field was further revolutionized and initiated-to develop and discover new biodrugs-, we noticed that this contributes to extend the life expectancy average $^{6}$ reflecting an important impact. According to a conservative valuation, the biopharmaceutical research and development onetime outlay is around 15billion US dollars then save approximately 1.6million life-years per annum, showing that the development of novel biodrugs plays a basic role in prolonging lifetime expectancy and extending healthy productive longevity and lifetime income by around $0.75 \%$ to $1.0 \%$ per year. $^{7}$

Lifetime average expectancy improved from 46.5 years for a person born in 1950-55 to 65.0 years for those born in 1995-2000 according to the United Nations datum. Such observations support that the new biodrugs have a substantial role in decreasing mortality and premature death average. ${ }^{8}$ Moreover, the biopharmaceutical innovation has also numerous economic outcomes and other benefits that cannot be neglected. Indeed, the availability, the abundance and the divers variety of several new biodrugs in the market result in the prices reduction of some medicines, increase drug accessibility and further develop the drug market. ${ }^{9,10}$ Such development in the biodrug innovation makes that the doctors and the healers have a variety of therapeutic options and curative choices to treat their patients. Thus, in case some of the biodrug is not suitable, cannot improve their health or have serious side effects if given to a specific patient, they may prescribe a different biodrug from the same category ${ }^{11}$ as an alternative. Laboratories and biopharmaceutical firms ensure and guarantee their funding continuity via, at least partially, the continuous innovation and discoveries. Indeed, it is accepted that the more they invent and innovate the more they get financial incomes.

This makes the biopharmaceutical firms relying on diver's sources of income and their financial fund box rich due to the development and innovation which are the future of every company. Such concept pushes to innovate and invest in biodrugs research and development 
along with the marketing of new medicines. ${ }^{22}$ The research and development boost the economy toward an economic growth and prosperity of the firm, and the civil society as a whole, via creating good values to enhance life features ${ }^{13,14}$ because there are important interaction and strong relationship between the economic growth and the productivity. When the health outcomes are advanced this will result in a decrease in diseases and disabilities which contributes to a revolution in the development and prosperity of the society. ${ }^{15,16}$

\section{Illustration of the challenges facing biopharmaceutical innovation}

Nowadays the biopharmaceutical companies, the health professionals and the stakeholders are facing a lot of challenges and struggles during the innovation of the new biodrugs and before the promotion of these novel products. For instance, according to the pharmaceutical protocols, every biodrug goes through many steps and procedures before the marketing, and among these stages, we have the animals and clinical studies. Indeed, this new medicine would be tested on the laboratory animals during the development process, sometimes there are a shortage and lack of this animal samples or restrictions on their usage because there are associations and animal rights authority which consider the use of some animals in scientific tests or other scientific purpose a kind of torture and consider this as an unethical issue, which is a big challenge that the biopharmaceutical innovation is facing ${ }^{17}$ while developing new therapeutic agents. Following the same line of thoughts, the European Union political platform and its Scientific Committee on Health and Environmental Risks, and in order to avoid animal extinction and for animal protection, suggest to amend and reconsider the use of non-human primates in clinical experiments and made new laws to protect some animals used for clinical tests.

Regarding this case, the use of human sample average is predictably in the way of rising..$^{18}$ Furthermore, another challenge the biodrugs innovation is facing is the lack and the insufficiency of financial resources that support research in the biopharmaceutical research and development. Moreover, the lack of experience and qualified individuals in some countries is also another issue biopharmaceutical innovation is facing. In addition, the research and development depends also on other different facts including the poverty, the regime of the country and the country policy. Obviously, the developed countries innovate more than the developing countries and the democratic countries innovation average is clearly higher than autocratic countries. ${ }^{19,20}$ In some situations, the biopharmaceutical market produces and promotes a new biodrug which is similar to another existing biodrug, ${ }^{21}$ but this medicines are not made according to the "copy past" method, this new biodrugs just belong to the same treatment category and treat the same kind of illness but their formulation, posology, composition or the cure condition and cure rapidity might be different. Such drugs have specific regulations in different countries.

Biopharmaceutical innovation got a lot of criticism which might affect their reputation; this is considered as one of the big challenges which the pharmaceutical firms are confronted to. ${ }^{22}$ Ethical challenges are also among the issue biopharmaceutical innovation has to deal with. In fact, before being promoted in the market, the drug goes through many steps while it is developed to become eligible to be marketed. Innovating a new biodrug is confronted to many ethical challenges at different levels. For instance, a discussion and a lot of questions were about the ethical issue of the use of placebo versus active compounds in pharmacological studies. In some cases, it is considered to have a negative impact on the clinical research because the issue with the placebo is that the patient should show his satisfaction and agreement for using this delusory therapy. Indeed when the individual participating in the scientific study does not receive an active and real therapy, it might be considered, by some professionals, as an unethical issue which stand in the front gate of the biopharmaceutical innovation as a big challenge. ${ }^{23-25}$

\section{Conclusion and perspectives}

The immense progress of biotechnology during the last decades represents the impulse behind the overall changes in process of the biodrugs innovation in several sectors and at different levels. Innovation is the element engine in this operation; when there is collaboration between manufacturers, scientific community and the society to encourage the innovation, it will surely have an impact in terms of saving lives and improving the public health at divers levels. In addition, it will especially ensure a healthy area for the coming generations since one of the best ways to improve the future is to innovate it.

\section{Acknowledgments}

We acknowledge the Jiangsu Overseas Research \& Training Program for University Prominent Young \& Middle-aged Teachers. Kadour Ghanemi is the recipient of a full scholarship from the China Scholarship council. Abdelaziz Ghanemi provided guidance and partial assistance in revising the manuscript.

\section{Conflict of interest}

The authors declare that there is no conflict of interest.

\section{References}

1. WO Siyanbola, OG Oladipo, AA Oyewale, et al. Academia-Industry Interactions in Nigeria Pharmaceutical Innovation System. Procedia Social and Behavioral Sciences. 2012;52(11):279-289.

2. Halim N, J Doyle. DR1 Public Health Innovation: Biopharmaceuticals Lost in Translation? Value in Health. 2012;15(4):A6.

3. Giovanna Lo Nigro, Azzurra Morreale, Gianluca Enea. Open innovation: A real option to restore value to the biopharmaceutical R\&D. International Journal of Production Economics. 2014;149:183-193.

4. Lieven Annemans, Irina Cleemput, Frank Hulstaert, et al. Stimulating pharmaceutical innovation in the EU. Expert Review of Pharmacoeconomics \& Outcomes Research. 2011;11(3):235-239.

5. Baker D, Fugh-Berman A. Do New Drugs Increase Life Expectancy? A Critique of a Manhattan Institute Paper. $J$ Gen Intern Med. 2009;24(5):678-682.

6. Haas M, Mantua V, Haberkamp M, et al. The European Medicine's Agency's strategies to meet the challenges of Alzheimer disease. Nat Rev Drug Discov. 2015;14(4):221-222.

7. Frank R Lichtenberg. Pharmaceutical Innovation, Mortality Reduction and Economic Growth. NBER working paper Number. 1998;6569.

8. Lichtenberg FR. The Impact of New Drug Launches on Longevity: Evidence from Longitudinal, Disease-Level Data from 52 Countries, 1982-2001. Int J Health Care Finance Econ. 2005;5(1):47-73.

9. Joseph A DiMasi. Price trends for prescription pharmaceuticals 19951999. Department of Health and Human Services' Conference on Pharmaceutical Pricing Practice. Washington, USA: Utilization and Costs; 2000. 
10. Ghanemi A. International drugs markets database to improve global drugs accessibility. Res Social Adm Pharm. 2017 ;13(4):880-881.

11. Valentin Petkantchin. Les avantages de l'innovation pharmaceutique graduelle. institur économique Molinari Avril. 2012;1-4.

12. Rajan Varadarajan. Fortune at the bottom of the innovation pyramid: The strategic Business. 2009;26(1):21-29.

13. Samanen J. Introduction to Biological and Small Molecule Drug Research and Development. Elsevier. 2013;471:225-253.

14. Lee SM, S Trimi. Innovation for creating a smart future. Journal of Innovation \& Knowledge. 2016;6(1):1-4.

15. Archibugi D. Blade Runner economics: Will innovation lead the economic recovery? Forthcoming in Research Policy. 2017;46(3):535-543.

16. $\mathrm{Hu} \mathrm{H}$, Chung CC. Biopharmaceutical Innovation System in China: System Evolution and Policy Transitions (Pre-1990s-2010s). International Journal of Health Policy and Management. 2015;4(12):823-829.

17. Geoffrey Tucker, Binodh De Silva, Jennifer Dressman, et al. Current Challenges and Potential Opportunities for the Pharmaceutical Sciences to Make Global Impact: An FIP Perspective. Journal of Pharmaceutical Sciences. 2016;105(9):2489-2497.
18. Prescott MJ. Ethics of primate use. Adv Sci Res 2010;5(1):1-22.

19. Berger M, Murugi J, Buch E, et al. Strengthening pharmaceutical innovation in Africa. Council on Health Research for Development (COHRED); New Partnership for Africa's Development (NEPAD). 2010;1(4):16-17.

20. Gao Y. Does democracy cause innovation? An empirical test of the popper hypothesis. Research Policy. 2017.

21. J Cohen, L Cabanila J Sosnov. Role of follow-on drugs and indications on the WHO Essential Drug List. Journal of Clinical Pharmacy and Therapeutics. 2006;31(1):585-592.

22. Albert I. Wertheimer and Thomas M Santella (2005) Pharmocoevolution: the benefits of incremental innovation. International Policy Network Available.

23. Laura Weiss Roberts, John Lauriello, Cynthia Geppert, et al. Placebos and paradoxes in psychiatric research: an ethics perspective. Biological Psychiatry. 2000;49(11):887-893.

24. Anne Harrington. The placebo effect. USA: Harvard University Press; 2000. 